\title{
COMPORTAMENTO INDIVIDUAL DE PLANTAS ORIGINADAS DE SEMENTES COM DIFERENTES NIIVEIS DE QUALIDADE FISIOLÓGICA EM POPULAÇÕES DE ARROZ IRRIGADO $^{1}$
}

\author{
PAULO TRAJANO BURCKSANTOS MELO ${ }^{2}$, LUIS OSMARBRAGASCHUCH ${ }^{3}$, FRANCISCO NETO DEASSIS $^{3}$, GERMANI CONCENÇO 4
}

\begin{abstract}
RESUMO - Com o objetivo de avaliar o comportamento individual de plantas originadas de sementes de alto e baixo vigor em populações de arroz irrigado (Oryza sativa L.), constituídas de diferentes combinações de distribuição ao longo da linha de semeadura, foi conduzido este estudo. O experimento constou de diferentes combinações de distribuição de sementes de arroz, cv. BRIRGA 410, oriundas de lotes de alto e baixo vigor, semeadas em ambiente controlado e, após, transplantadas ao campo para garantir o estande de plantas e o arranjo da semeadura. Para tal, foram avaliados altura, matéria seca da planta e número de perfilhos aos 60,102 e 134 dias após transplante ao campo e número de panículas por planta, rendimento de grãos e índice de colheita, ao final do ciclo. As plantas originadas de sementes de alto vigor apresentaram desempenho superior para todas as características avaliadas, independentemente do sistema de distribuição das plantas ao longo da linha de semeadura. As plantas originadas de sementes de alto vigor apresentaram rendimento médio de grãos superior ao das plantas originadas de sementes de baixo vigor. Plantas de arroz originadas de sementes de alto vigor não apresentam desempenho dominante sobre as plantas adjacentes de baixo vigor na linha de semeadura.
\end{abstract}

Termos para indexação: Oryza sativa, vigor, rendimento de grãos.

\section{INDIVIDUALBEHAVIOR OF RICE PLANTS FROM DIFFERENT PHYSIOLOGICALQUALITY SEEDS IN RICE POPULATIONS}

\begin{abstract}
With the objective of to evaluate the individual behaviour of rice plants from high and low physiological quality seeds in populations of rice (Oryza sativa L.) under different combinations along the sowing line, this study was conducted. The treatments were composed of different mixes of rice, cv. BR-IRGA 410, seeds of low and high vigor, sowed under controlled environment and transplanted to the field, in order to maintain homogeneous stand and arrangement of seedlings. Height, dry mass and branches number were evaluated at 60,102 and 134 days after transplanting and grain yield, harvest index and number of panicles per plant were evaluated at the end of the cycle. Plants originated from high physiological quality seeds were superior in all parameters evaluated, with no significance of plant position along the line. Plants from high vigor seeds showed grain yield increasing when compared to plants from low vigor seeds, and did not show a dominating behaviour over the plants originated from low vigor seeds.
\end{abstract}

Index terms: Oryza sativa, vigor, grain yield.

\footnotetext{
${ }^{1}$ Submetido em 09/05/2005. Aceito para publicação em 18/11/2005. Parte da tese de doutorado do primeiro autor apresentada à FAEM-UFPel;

${ }^{2}$ Doutor em Agronomia, UFPel/FAEM, ptmelo@brturbo.com.br;
}

\footnotetext{
${ }^{3}$ Professor, Dr., Departamento de Fitotecnia, UFPel/FAEM, Caixa Postal 354, CEP: 96010-900;

${ }^{4}$ Mestre em Fisiologia Vegetal, UFPel/IB.
} 


\section{INTRODUÇÃO}

O estudo do desenvolvimento de plantas em comunidade é diferente do estudo de plantas isoladas e, portanto, livre dos efeitos de competição dentro da comunidade. A competição de plantas pelos recursos do meio ambiente pode ocorrer entre plantas de mesma espécie e plantas de espécies diferentes. A competição entre plantas de espécies diferentes causa graves danos à agricultura pelo comprometimento do rendimento econômico causado pelas plantas invasoras, mais eficientes na disputa pelos recursos.

Existem diversos estudos em relação à densidade de semeadura das culturas, no entanto, o efeito da competição entre plantas de uma mesma espécie ainda necessita ser estudada, pois cada planta reage de maneira diferenciada à competição por um ou mais fatores. As respostas obtidas variam em função do estádio em que as plantas se encontram, da densidade de plantas e das condições ambientais. Plantas que emergem precocemente podem apresentar melhores condições de competir com as plantas emergidas tardiamente, sujeitas a disputar com as primeiras os recursos limitados disponíveis no ambiente.

A competição é definida como interação entre membros da mesma população ou de duas ou mais populações, a fim de obter recurso mutuamente necessário e disponível em quantidade limitada. A maneira como as plantas individualmente são capazes de aumentar seu crescimento como um todo e assim competir por luz, água e nutrientes minerais determina, em grande parte seu sucesso em diferentes ambientes. $\mathrm{O}$ conhecimento desses fatores e de seus inter-relacionamentos fornecerá as informações para predizer o desempenho de espécies e comunidades em ambiente com constantes mudanças (Raven et al., 2001). Henning e Ferraz (1983) também mencionam a competição entre os seres vivos, como a concorrência por melhores condições de vida, podendo existir entre espécies e entre indivíduos de uma mesma espécie.

Uma planta não compete com outra enquanto o conteúdo de água, nutrientes, luz e temperatura estão acima das necessidades de ambas. Quando o suprimento imediato de um único fator necessário diminui abaixo da demanda combinada das plantas, a competição tem início. Os fatores pelos quais as plantas podem competir são água, nutrientes, luz, oxigênio e dióxido de carbono, entretanto na fase reprodutiva ocorre competição por agentes de polinização e de dispersão (Donald, 1963).

Durante a fase vegetativa, as plantas estão no máximo de suas atividades metabólicas (fotossíntese, respiração e absorção de substâncias minerais). Do ponto de vista da competição por espaço nas comunidades vegetais, o rápido crescimento da parte aérea, sistema radicular e partes responsáveis pela reprodução vegetativa será decisivo para o futuro do indivíduo, pois é durante a fase de crescimento que se manifestam as características de plasticidade fenotípica e, sobretudo, as ações modificativas em relação às condições do habitat (Larcher, 2000).

Segundo Freckleton e Watkinson (2001), o conhecimento das forças de interações entre espécies em comunidades de planta é de importância fundamental para compreender como as comunidades são estruturadas, embora seja difícil quantificar essas forças.

A competição entre plantas depende de várias características, como a morfologia da planta, capacidade de extrair água e nutrientes do solo, diferentes respostas à temperatura, exigência diferencial por luz, entre outros. O efeito da competição sobre o desenvolvimento e produção das plantas é variável e os resultados dependem do estádio de desenvolvimento no qual esta ocorre (Castro e Garcia, 1996). Assim, o arranjo entre plantas pode ser utilizado para minimizar o efeito da competição intraespecífica (Agostinetto et al., 2001).

Nas plantas cultivadas a competição é um fator importante pois afeta o rendimento de colheita. O entendimento dos fatores que controlam a variabilidade fenológica é crucial para o desígnio de práticas de controle de plantas daninhas. Os fatores que controlam a variabilidade na germinação de sementes, desenvolvimento da arquitetura, florescimento e produção de semente são particularmente importantes (Ghersa, 2000).

A plasticidade, segundo Donald (1963), é uma característica das plantas de explorar tanto um meio mais favorável ou mais amplo, como a capacidade de sobreviver e se reproduzir em ambiente com recursos escassos. Esta característica evidencia uma habilidade competitiva nas plantas invasoras.

O aumento da fitomassa da comunidade não significa selecionar plantas mais vigorosas, mas sim plantas que, em densidade adequada, manifestam seu crescimento máximo. No entanto, isso nem sempre é vantajoso, pois muitas vezes o incremento de matéria seca não ocorre na parte econômica da cultura. Além disso, é necessário que as plantas da comunidade permitam que as plantas vizinhas também possam manifestar esta característica.

O objetivo deste trabalho foi avaliar o desempenho individual de plantas de arroz originadas de sementes de alto $\mathrm{e}$ 
baixo vigor, em populações constituídas de diferentes combinações de distribuição destas plantas ao longo da linha de semeadura.

\section{MATERIAL E MÉTODOS}

O experimento foi conduzido na Universidade Federal de Pelotas (UFPel), Capão do Leão/RS, no ano agrícola 2002/ 03, em delineamento experimental de blocos casualizados, com 4 repetições. A semeadura foi realizada em sistema convencional e a correção da fertilidade foi realizada de acordo com análise de solo baseado nas normas da ROLAS (1994), sendo incorporado ao solo, antes do transplante, $60 \mathrm{~kg} \cdot \mathrm{ha}^{-1} \mathrm{de}$ $\mathrm{P}_{2} \mathrm{O}_{5}, 40 \mathrm{~kg} \cdot \mathrm{ha}^{-1}$ de $\mathrm{K}_{2} \mathrm{O}$ e $60 \mathrm{~kg} \cdot \mathrm{ha}^{-1}$ de N. A adubação nitrogenada foi dividida em três épocas, $1 / 3$ incorporada antes do transplante, $1 / 3$ no perfilhamento e $1 / 3$ na diferenciação do primórdio floral.

Foram utilizadas sementes fiscalizadas de arroz irrigado, cultivar BR-IRGA 410, de dois lotes devidamente caracterizados como de alto e baixo vigor, em diferentes arranjos. O lote considerado de alto vigor (Brasil, 1992; Vieira e Carvalho, 1994) apresentava 51\% de germinação na primeira contagem realizada aos sete dias e $96 \%$ de germinação na avaliação final aos 14 dias, com índice de velocidade de germinação (IVG) de 17,4. O lote considerado de baixo vigor apresentava $27 \%$ de germinação na primeira contagem realizada aos sete dias e $81 \%$ de germinação na avaliação final aos 14 dias, com IVG de 13,0.

A semeadura foi realizada em bandejas contendo vermiculita no dia 13/11/2002, para posterior transplante no campo. Após a emergência, foram eliminadas as plantas precoces entre as de baixo vigor e as tardias entre as de alto vigor. Quinze dias após a semeadura, as plântulas emergidas foram transplantadas no campo, com distância entre linhas de $20 \mathrm{~cm}$ e 2,5cm entre plantas ao longo da linha de semeadura.

Não foram necessários tratamentos fitossanitários e o controle de plantas invasoras foi realizado manualmente, o mais precoce possível para evitar o efeito da competição com as plantas do experimento.

Os tratamentos constaram de cinco arranjos de plantas constituídos por combinações de distribuição de plantas originadas de sementes de baixo (B) e alto vigor (A) transplantadas ao longo da linha de semeadura. Os arranjos de plantas obtidos por transplante foram os seguintes:

1. todas as plantas originadas de sementes de alto vigor (AAAA);
2. uma planta originada de semente de alto vigor e outra de baixo vigor (ABAB);

3. uma planta originada de semente de alto vigor e duas de baixo vigor (ABBA);

4. uma planta originada de semente de alto vigor e três de baixo vigor (ABBBA);

5. todas as plantas originadas de sementes de baixo vigor (BBBB).

Na combinação ABBBA foram avaliadas separadamente as plantas provenientes de sementes de baixo vigor localizadas imediatamente ao lado das plantas originadas de sementes de alto vigor, na linha de semeadura, e as localizadas na posição intermediária entre duas plantas de baixo vigor. Para fins de avaliação receberam a denominação de $B_{1}$ e $B_{2}$, respectivamente.

As três coletas de plantas para análise foram realizadas aos 60, 102 e 134 dias após transplante (DAT). As determinações foram conduzidas individualmente com 10 plantas de cada posição na semeadura. Estas plantas coletadas de cada seqüência de semeadura foram avaliadas individualmente. Por ocasião da colheita, as plantas foram cortadas rente ao solo e identificadas individualmente, possibilitando a determinação da posição dentro do arranjo do campo. Estas foram colocadas em sacos plásticos com algodão umedecido e levadas até o Laboratório Didático de Análise de Sementes, Faculdade de Agronomia Eliseu Maciel. O comprimento da parte aérea foi avaliado com a utilização de régua graduada, em centímetros. Após, a determinação da área foliar em determinador de área foliar Licor (Lambda Instruments Corporation), realizou-se a contagem do número de afilhos, número de panículas e número de grãos, bem como a retirada dos grãos para serem levadas ao secador. Após a secagem foi realizada a pesagem, utilizando-se balança centesimal e a determinação da umidade foi realizada com aparelho Dickey-John, modelo Multi-Grain, para obter a produção por planta. A determinação do rendimento de grãos por parcela foi realizada a partir da média da soma da produção das plantas individuais. Após a trilha das panículas de cada planta foi determinada a produção por planta de cada posição de semeadura. A determinação de matéria seca foi realizada em estufa a $60^{\circ} \mathrm{C}$ por 72 horas, permitindo a determinação do rendimento biológico.

A análise de variância foi realizada pelo teste $\mathrm{F}$ a $5 \%$ e, quando significativo, executou-se comparação de médias pelo teste de Scott Knott, ao nível de 5\% de probabilidade. 


\section{RESULTADOS E DISCUSSÃO}

Os resultados obtidos para a variável resposta matéria seca de plantas permitem observar uma estratificação acentuada na primeira época (60 DAT). Aos 102 DAT, as plantas originadas de sementes de alto vigor continuaram a se destacar, repetindo este resultado por ocasião da colheita (Figura 1). Desta forma, observou-se na colheita que as plantas originadas de sementes de alto vigor apresentavam maior incremento de matéria seca.
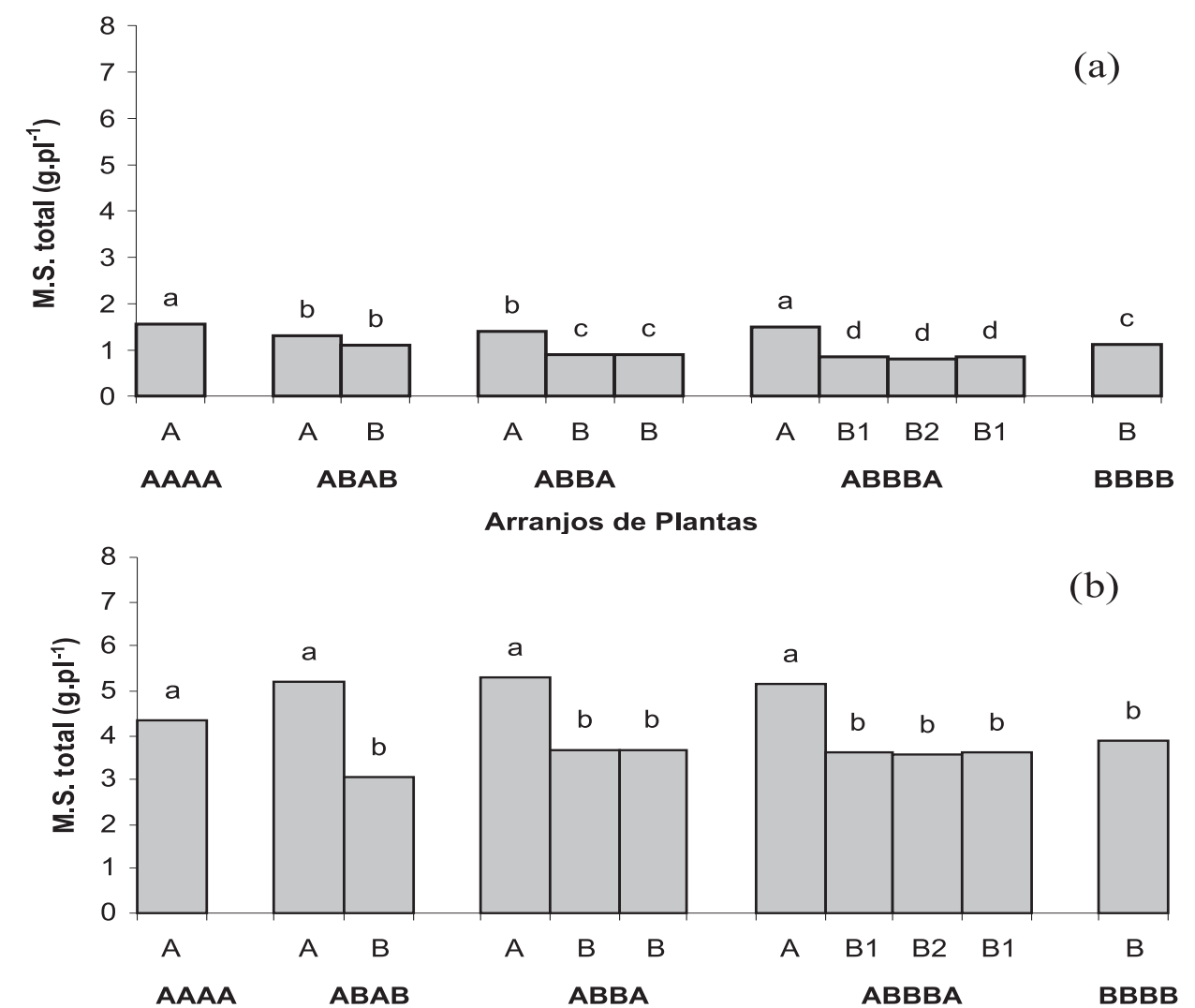

Arranjos de Plantas

(c)

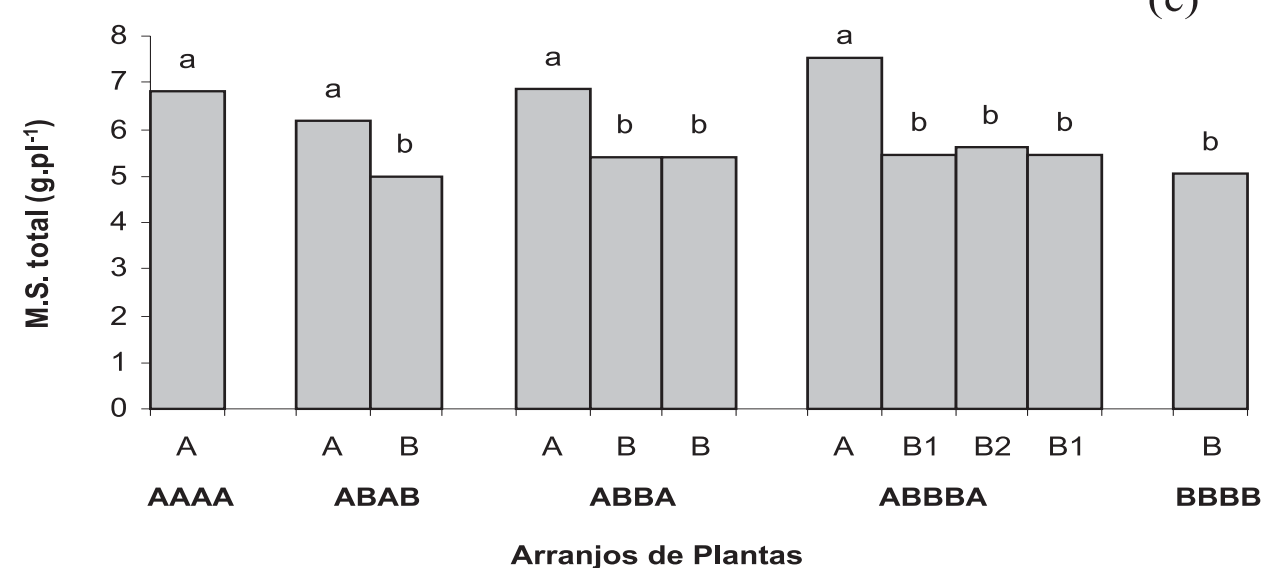

FIGURA 1. Matéria seca total de plantas individuais de arroz dentro das comunidades constituídas pelos diferentes arranjos de plantas, em gramas.planta-1, aos (a) 60, (b) 102 e (c) 134 DAT, Capão do Leão, RS 2002/2003. A- Plantas originadas de sementes de alto vigor dentro do arranjo de plantas. B - Plantas originadas de sementes de baixo vigor dentro do arranjo de plantas. $B_{1}$ - Plantas originadas de sementes de baixo vigor dentro do arranjo de plantas, localizadas imediatamente ao lado das plantas originadas de semente de alto vigor. $B_{2}$ - Plantas originadas de sementes de baixo vigor dentro do arranjo de plantas, localizadas entre duas plantas de baixo vigor. Médias com mesma letra não diferem pelo teste de Scott-Knott a $5 \%$ de probabilidade. 
A área foliar aos 60 DAT apresentou resultados com tendência de melhora para as plantas originadas de sementes de alto vigor. Na segunda e terceira épocas, a superioridade das plantas originadas de sementes de alto vigor foi confirmada (Figura 2).
As diferenças observadas para altura de plantas aos 60 DAT, quando as plantas originadas de sementes de alto vigor se destacaram, foram atenuadas durante a segunda e terceira épocas de avaliação aos 102 e 134 DAT (Figura 3).

O número de perfilhos por plantas, na primeira época,

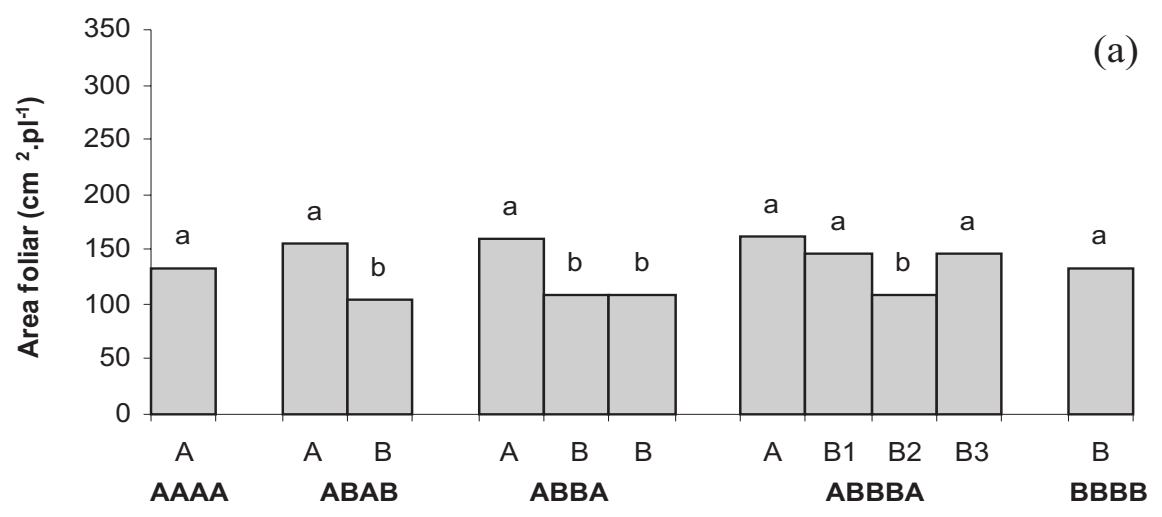

Arranjo de Plantas

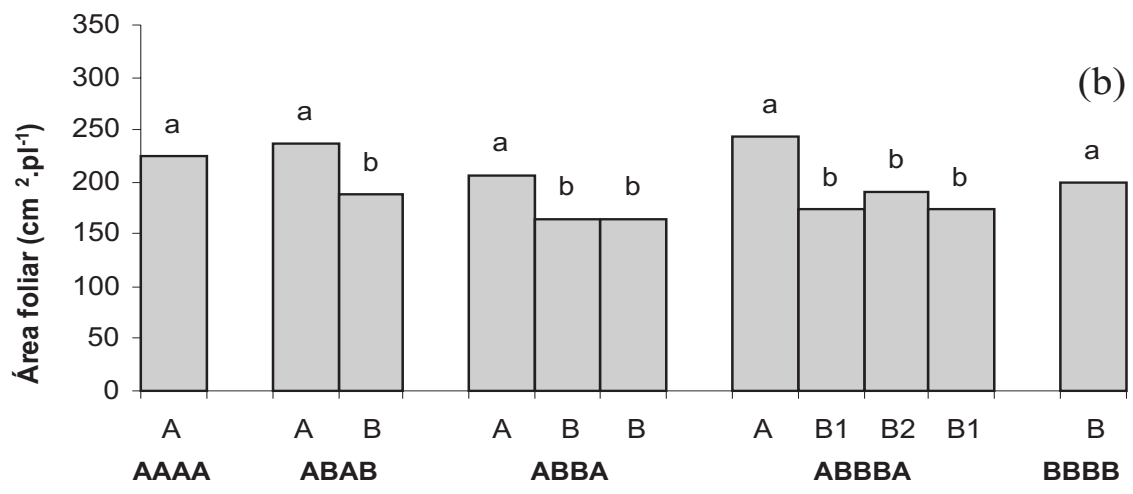

Arranjo de Plantas

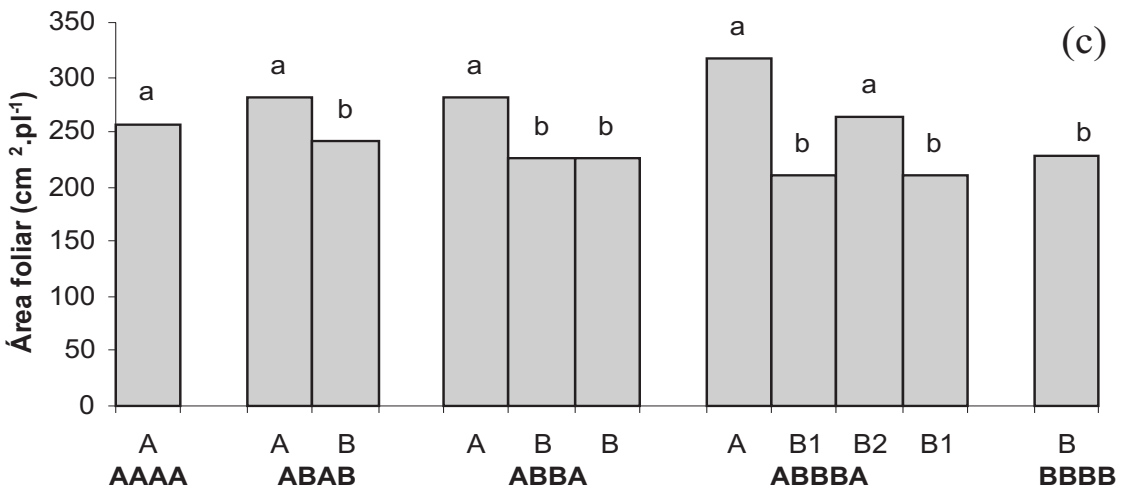

Arranjos de Plantas

FIGURA 2. Área foliar de plantas individuais de arroz dentro de comunidades constituídas pelos diferentes arranjos de plantas, em $\mathrm{cm}^{2}$.planta $^{-1}$, aos (a) 60, (b) 102 e (c) 134 DAT Capão do Leão, RS 2002/2003. A - Plantas originadas de sementes de alto vigor dentro do arranjo de plantas. $B$ - Plantas originadas de sementes de baixo vigor dentro do arranjo de plantas. $B_{1}$ Plantas originadas de sementes de baixo vigor dentro do arranjo de plantas, localizadas imediatamente ao lado das plantas originadas de semente de alto vigor. $B_{2}$ - Plantas originadas de sementes de baixo vigor dentro do arranjo de plantas, localizadas entre duas plantas de baixo vigor. Médias com mesma letra não diferem pelo teste de Scott-Knott a $5 \%$ de probabilidade. 
foi maior para as plantas originadas de sementes de alto vigor (Figura 4). Observou-se que durante a época de colheita nem todos os perfilhos eram férteis, pois nem todos apresentavam panículas.
O número de panículas por planta (Figura 5), rendimento de grãos (Figura 6) e rendimento biológico (Figura 8) seguiram a tendência das demais variáveis com nítida superioridade das plantas originadas de sementes de alto vigor. Enquanto

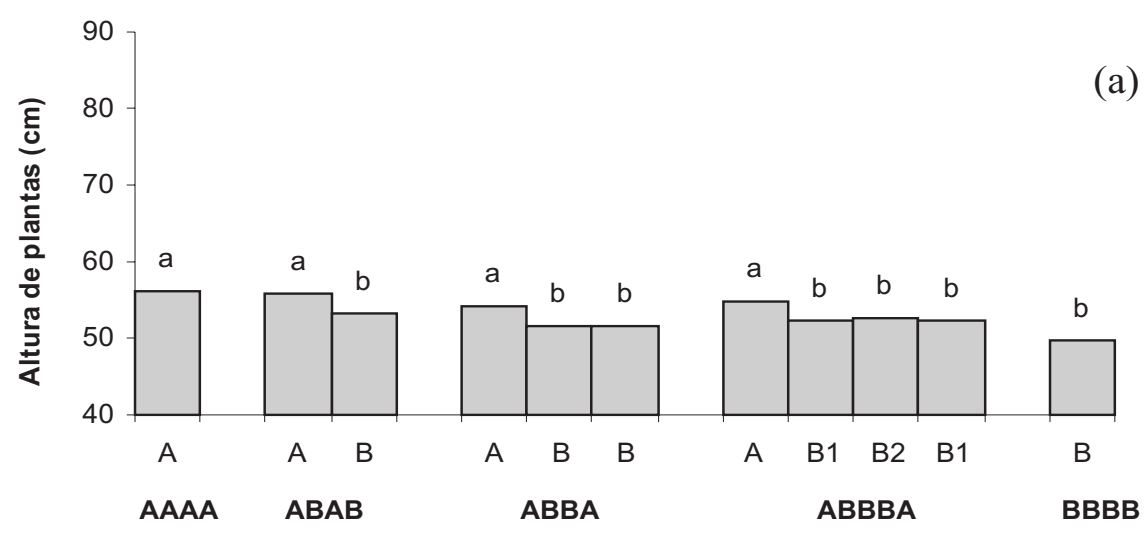

Arranjos de Plantas

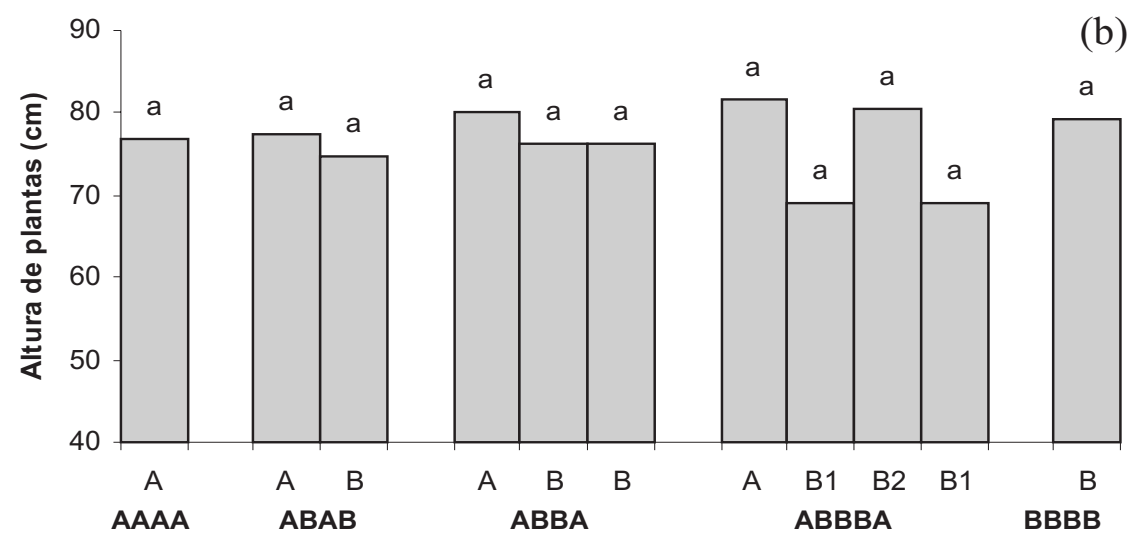

Arranjos de Plantas

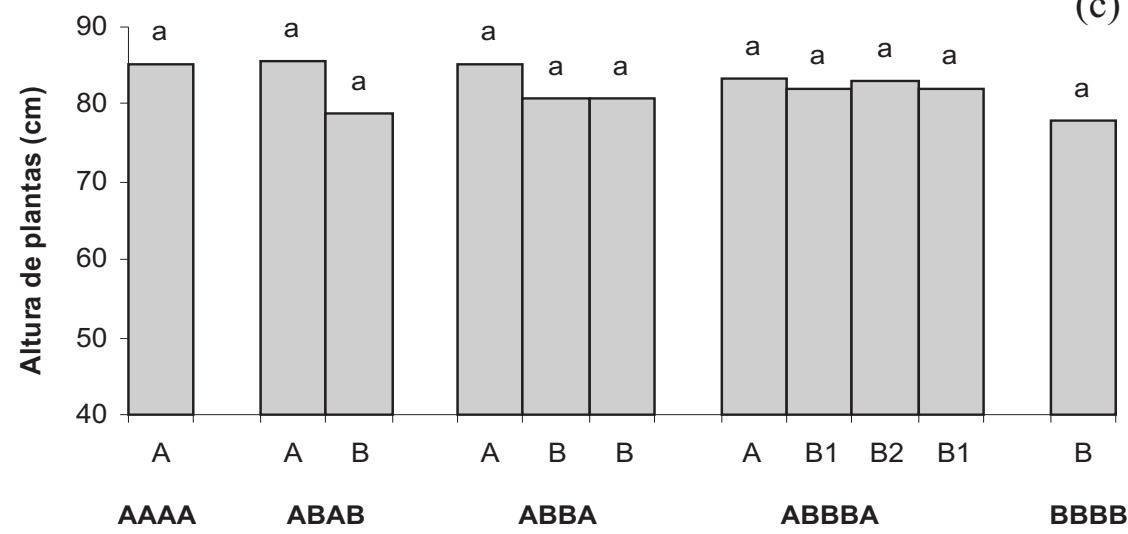

Arranjos de Plantas

FIGURA 3. Altura de plantas individuais de arroz dentro de comunidades constituídas pelos diferentes arranjos de plantas, em centímetros, aos (a) 60, (b) 102 e (c) 134 DAT. Capão do Leão, RS 2002/2003. A-Plantas originadas de sementes de alto vigor dentro do arranjo de plantas. $B$ - Plantas originadas de sementes de baixo vigor dentro do arranjo de plantas. $B_{1}$ Plantas originadas de sementes de baixo vigor dentro do arranjo de plantas, localizadas imediatamente ao lado das plantas originadas de semente de alto vigor. $B_{2}$ - Plantas originadas de sementes de baixo vigor dentro do arranjo de plantas, localizadas entre duas plantas de baixo vigor. Médias com mesma letra não diferem pelo teste de Scott-Knott a $5 \%$ de probabilidade. 
que o peso de mil grãos não foi alterado, independente do tratamento (Figura 7).

Os dados da primeira época de avaliação coincidiram com os obtidos por Höfs et al. (2004), pois as plantas originadas de sementes de baixo vigor tiveram sua emergência retardada nas bandejas, simulando condições de emergência em campo. Além disso, o maior rendimento de grãos observado para plantas oriundas de sementes de alto vigor (Figura 6) está de acordo com os observados por Schuch et al. (2000) em aveia, Höfs et al. (2004) em arroz irrigado e Kolchinski et al. (2005)

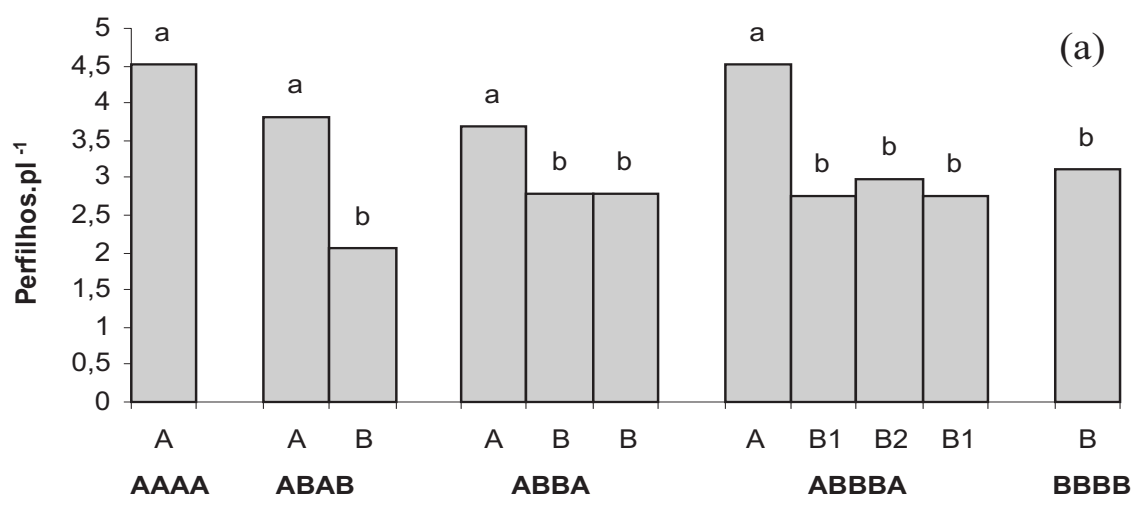

Arranjos de Plantas

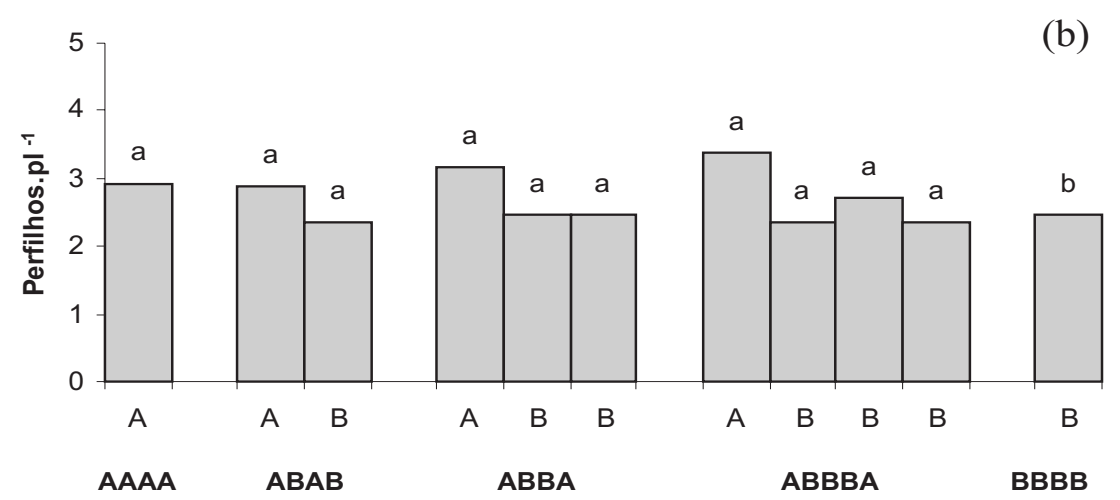

Arranjos de Plantas

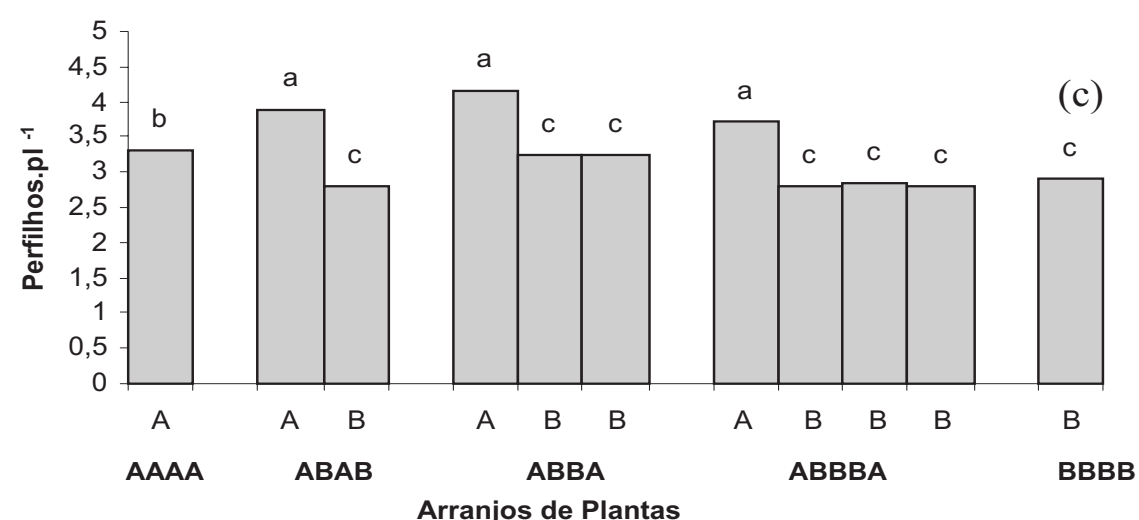

FIGURA 4. Perfilhos por plantas individuais de arroz dentro das comunidades constituídas pelos diferentes arranjos de plantas aos (a) 60, (b) 102 e (c) 134 DAT. Capão do Leão, RS 2002/2003. A- Plantas originadas de sementes de alto vigor dentro do arranjo de plantas. $B$ - Plantas originadas de sementes de baixo vigor dentro do arranjo de plantas. $B_{1}$ - Plantas originadas de sementes de baixo vigor dentro do arranjo de plantas, localizadas imediatamente ao lado das plantas originadas de semente de alto vigor. $B_{2}$ - Plantas originadas de sementes de baixo vigor dentro do arranjo de plantas, localizadas entre duas plantas de baixo vigor. Médias com mesma letra não diferem pelo teste de Scott-Knott a 5\% de probabilidade. 


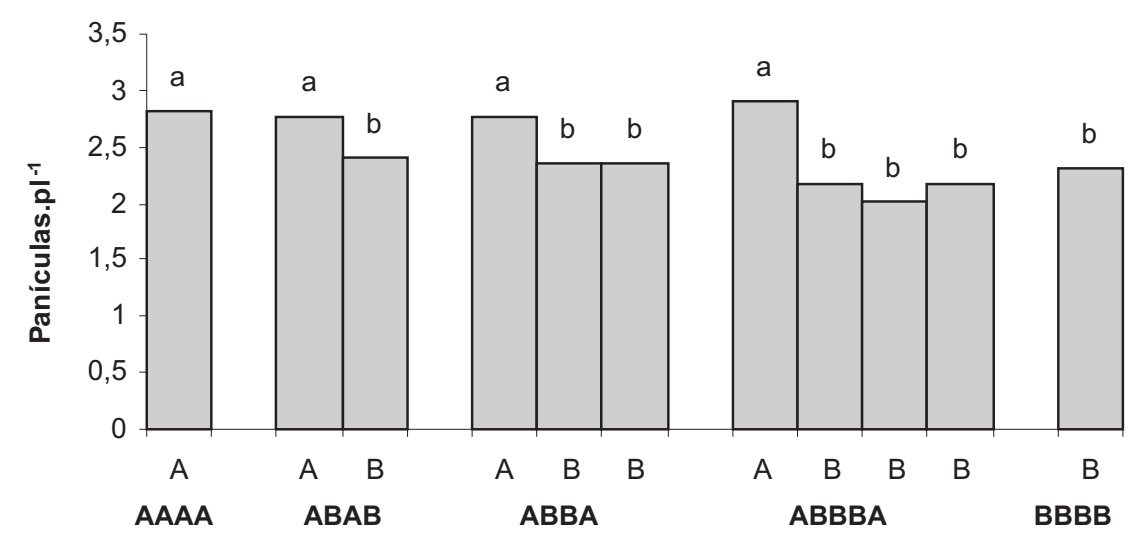

Arranjos de Plantas

FIGURA 5. Panículas por planta individuais de arroz dentro de comunidades constituídas pelos diferentes arranjos de plantas aos 134 DAT. Capão do Leão, RS 2002/2003. A - Plantas originadas de sementes de alto vigor dentro do arranjo de plantas. B - Plantas originadas de sementes de baixo vigor dentro do arranjo de plantas. $B_{1}$ - Plantas originadas de sementes de baixo vigor dentro do arranjo de plantas, localizadas imediatamente ao lado das plantas originadas de semente de alto vigor. $B_{2}$ - Plantas originadas de sementes de baixo vigor dentro do arranjo de plantas, localizadas entre duas plantas de baixo vigor. Médias com mesma letra não diferem pelo teste de Scott-Knott a $5 \%$ de probabilidade.

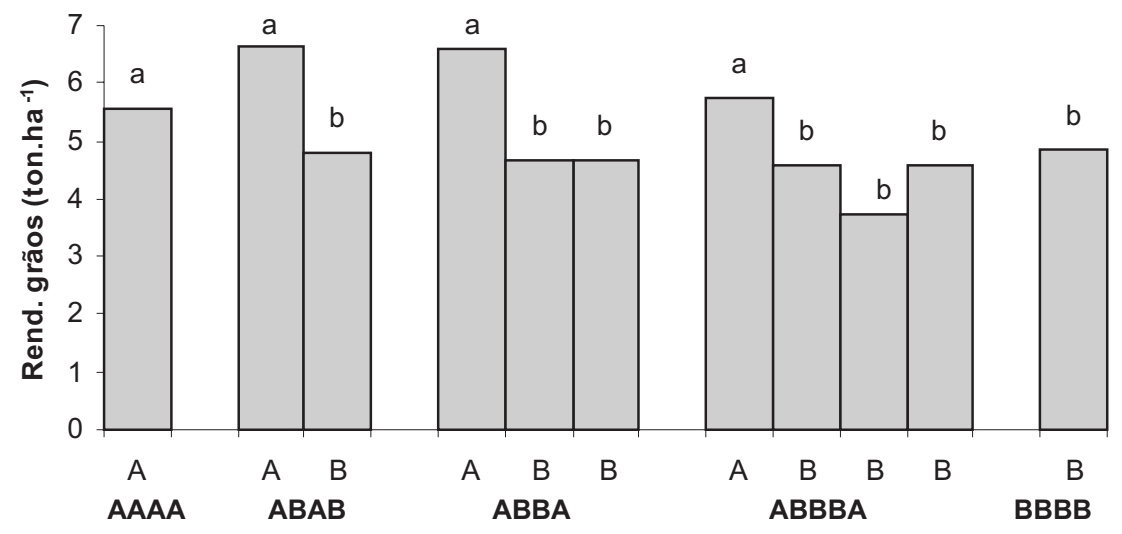

Arranjos de Plantas

FIGURA 6. Rendimento de grãos colhidos de plantas individuais de arroz dentro das comunidades constituídas pelos diferentes arranjos de plantas, em toneladas.ha ${ }^{-1}$, aos 134 DAT. Capão do Leão, RS 2002/2003. A-Plantas originadas de sementes de alto vigor dentro do arranjo de plantas. $B$ - Plantas originadas de sementes de baixo vigor dentro do arranjo de plantas. $B_{1}$ - Plantas originadas de sementes de baixo vigor dentro do arranjo de plantas, localizadas imediatamente ao lado das plantas originadas de semente de alto vigor. $B_{2}$ - Plantas originadas de sementes de baixo vigor dentro do arranjo de plantas, localizadas entre duas plantas de baixo vigor. Médias com mesma letra não diferem pelo teste de Scott-Knott a $\mathbf{5 \%}$ de probabilidade.

em soja. Mesmo a alta plasticidade da planta de arroz não foi suficiente para compensar o atraso no desenvolvimento causado pelo uso de sementes de baixo vigor, ou seja, o rendimento de grãos, que é a parte econômica da cultura, foi maior nas plantas oriundas de alto vigor.

Vale ressaltar ainda que o estande de plantas foi completo, ou seja, não ocorreram falhas na linha, condição muito difícil de se reproduzir no campo, o que poderia ser ainda mais crítico quando se utilizam sementes de baixa qualidade fisiológica.

Sementes de alta qualidade emergem rápida e uniformemente sob diferentes condições de ambiente (Egli, 1993). Desta forma, a utilização de sementes de alta qualidade é recomendada, pois, sob as condições do experimento, a 


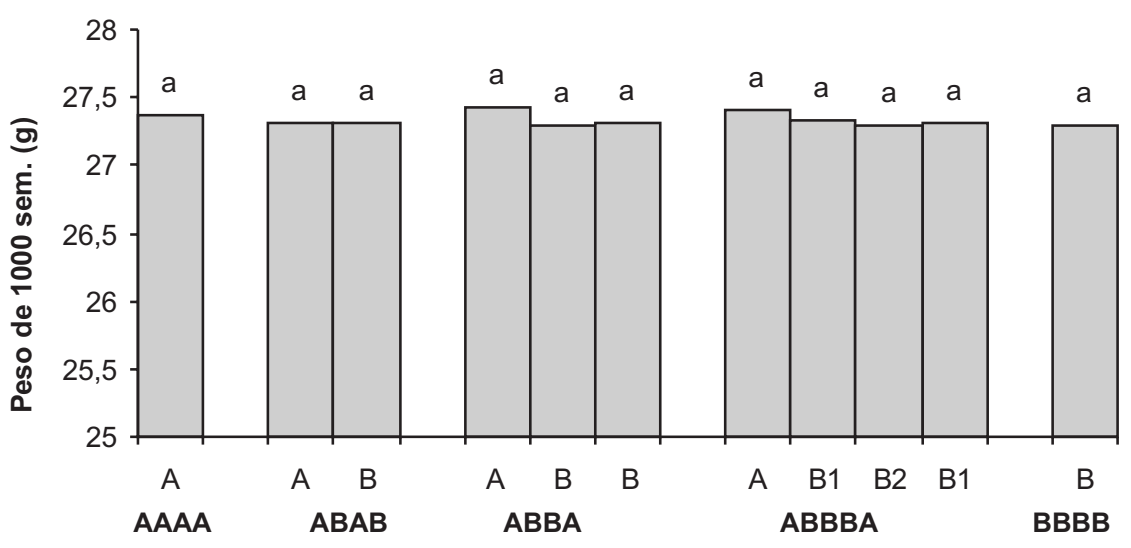

Arranjos de Plantas

FIGURA 7. Peso de 1000 sementes colhidas de plantas individuais de arroz dentro de comunidades constituídas pelos diferentes arranjos de plantas, em gramas, aos 134 DAT. Capão do Leão, RS 2002/2003. A-Plantas originadas de sementes de alto vigor dentro do arranjo de plantas. $B$ - Plantas originadas de sementes de baixo vigor dentro do arranjo de plantas. $B_{1}$ Plantas originadas de sementes de baixo vigor dentro do arranjo de plantas, localizadas imediatamente ao lado das plantas originadas de semente de alto vigor. $B_{2}$ - Plantas originadas de sementes de baixo vigor dentro do arranjo de plantas, localizadas entre duas plantas de baixo vigor. Médias com mesma letra não diferem pelo teste de Scott-Knott a $\mathbf{5 \%}$ de probabilidade.

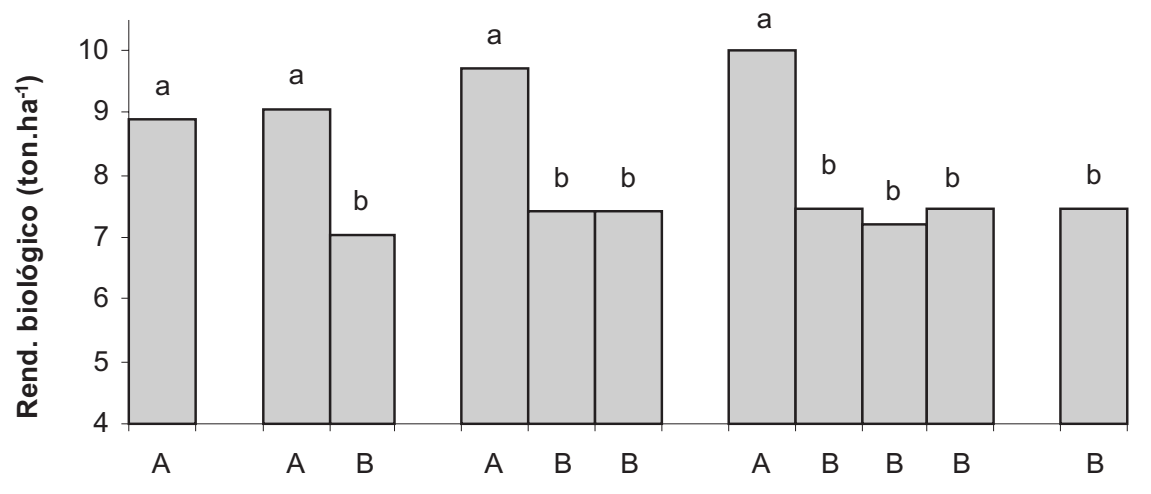

Arranjos de Plantas

FIGURA 8. Rendimento biológico de plantas individuais de arroz dentro das comunidades constituídas pelos diferentes arranjos de plantas, em toneladas.ha ${ }^{-1}$, aos 134 DAT. Capão do Leão, RS 2002/2003. A-Plantas originadas de sementes de alto vigor dentro do arranjo de plantas. B - Plantas originadas de sementes de baixo vigor dentro do arranjo de plantas. $B_{1}$ - Plantas originadas de sementes de baixo vigor dentro do arranjo de plantas, localizadas imediatamente ao lado das plantas originadas de semente de alto vigor. $B_{2}$ - Plantas originadas de sementes de baixo vigor dentro do arranjo de plantas, localizadas entre duas plantas de baixo vigor. Médias com mesma letra não diferem pelo teste de Scott-Knott a $5 \%$ de probabilidade.

plasticidade das plantas de arroz não foi suficiente para compensar o retardamento na emergência e o menor tamanho das plântulas para alguns atributos fisiológicos (Figuras $4 \mathrm{e}$ 6). Além do mais, lotes de baixo vigor podem apresentar sementes sem capacidade de emergir ou que apresentem grande debilidade por constituírem plântulas anormais ou de tamanho reduzido, causando falhas nas linhas de plantio, ou ainda, favorecendo a infestação de plantas daninhas.

As plantas originadas de sementes oriundas de lotes de alto vigor, de acordo com Höfs et al. (2004), são mais eficientes na produção de biomassa seca, sendo as diferenças reduzidas ao longo do ciclo da cultura, mesmo assim mensuráveis ao final do ciclo da cultura. Resultados similares foram observados, inclusive no final do ciclo da cultura (134 
DAT), onde as diferenças não foram completamente compensadas (Figuras 2, 4, 5, 6 e 8).

Trabalhando com desuniformidade na profundidade de semeadura de sementes de aveia, Almeida et al. (2001) concluíram que a competição intraespecífica resultante da desuniformidade na profundidade de semeadura afetou a alocação de massa seca nas plantas, determinando menor emissão de afilhos e menor alocação de matéria seca no colmo principal e afilhos. Como maior profundidade de semeadura resulta em emergência mais tardia, comportamento semelhante pode ser esperado com o uso de sementes de baixo vigor, como se observa nas Figuras 2, 3 e 4, onde a diferença inicial foi atenuada aos 102 DAT, mas voltou a se tornar pronunciada ao final do ciclo (134 DAT). Após a compensação inicial, as plantas B não possuíam capacidade de concorrer e se igualar as plantas $\mathrm{A}$.

O vigor inicial proporcionou melhores condições de captação da energia solar, favorecendo o desenvolvimento das plantas (Walker et al. 1988; Almeida et al., 1998), o que proporcionou maior rendimento de grãos para as plantas originadas de sementes de melhor qualidade fisiológica em todas as situações (Figura 6). Além disso, considerando a posição das plantas dentro do arranjo, os resultados indicam que as plantas originadas de sementes de alto vigor, quando em conjunto com plantas originadas de baixo vigor, apresentam tendência de se destacar no número de panículas por planta (Figura 5) e na produção por planta (Figura 6). Os dados de produção por planta (Figura 6) estão de acordo aos observados por Merotto Junior et al. (1999) que, trabalhando com desuniformidade na emergência de milho, constataram que as plantas que emergiram primeiro apresentaram maior rendimento de grãos, dominando as plantas tardias. Porém, a compensação não foi suficiente para garantir a produtividade. Além disso, estes mesmos autores concluíram que o uso de sementes de alto vigor, além do benefício no rendimento de grãos, tem por objetivo assegurar adequada população de plantas em variadas condições de campo durante a emergência, onde sementes de baixo vigor não teriam capacidade de suportar as condições ambientais desfavoráveis.

\section{CONCLUSÕES}

As plantas originadas de sementes de alto vigor apresentam desempenho superior em relação às originadas de sementes de baixo vigor para os parâmetros matéria seca de plantas, área foliar, altura, número de perfilhos, panículas por planta e rendimento biológico, independentemente do sistema de distribuição das plantas ao longo da linha de semeadura.

As plantas originadas de sementes de alto vigor apresentam rendimento de grãos superior às plantas originadas de sementes de baixo vigor.

Plantas de arroz originadas de sementes de alto vigor não apresentam comportamento dominante sobre as plantas adjacentes de baixo vigor na linha de semeadura.

\section{REFERÊNCIAS}

AGOSTINETTO, D.; FLECK, N.G.; RIZZARDI, M.A.; MEROTTO JR., A.; VIDAL, R.A. Arroz vermelho: ecofisiologia e estratégias de controle. Ciência Rural, Santa Maria, v.31, n.2, p.341-349, 2001.

ALMEIDA M.L.; MUNDSTOCK C.M.; SAGOI, L. Conceito de ideotipo e seu uso no aumento do rendimento potencial de cereais. Ciência Rural, Santa Maria, v.28, n.2, p.325-332, 1998.

ALMEIDA M.L.; MUNDSTOCK, C.M. O afilhamento da aveia afetado pela qualidade da luz em plantas sob competição. Ciência Rural, Santa Maria, v.31, n.3, p.393-400, 2001.

BRASIL. Ministério da Agricultura e Abastecimento e de Reforma Agrária. Regras para análise de sementes. Brasília: SNDA/DNDV/ CLAV, 1992.365p.

CASTRO, C.R.T.; GARCIA, R. Competição entre plantas com ênfase no recurso luz. Ciência Rural, Santa Maria, v.26, n.1, p.167$174,1996$.

DONALD, C.M. Competition among crop and pasture plants. Advances in Agronomy, New York, v.15, p.1-118, 1963.

EGLI, D.B. Relationship of uniformity of soybean seedling emergence to yield. Journal of Seed Technology, Lincoln, v.17, n.1, p.22-28, 1993.

FRECKLETON, R.P.; WATKINSON A.R. Nonmanipulative determination of plant community dynamics. Trends in Ecology \& Evolution, Amsterdam, v.16, n.6, p.301-307, 2001.

GHERSA, C.M. Plant phenology and the management of crop weed interactions. Field Crops Research, v.67, n.2, p.91-93, 2000.

HENNING, G.J.; FERRAZ, G.C. Biologia Geral. 12 ed., Porto Alegre: Mercado Aberto, 1983. 360p.

HOFS, A.; SCHUCH, L.O.B.; PESKE, S.T.; BARROS, A.C.S.A. Efeito da qualidade fisiológica das sementes e da densidade de semeadura sobre o rendimento de grãos e qualidade industrial de arroz. Revista Brasileira de Sementes, Pelotas, v.26, n.2, p.55-62, 2004.

LARCHER, W. Ecofisiologia vegetal. São Carlos: Rima Artes e Textos, 2000.531p.

KOLCHINSKI, E.M.; SCHUCH, L.O.B.; PESKE, S.T. Vigor de sementes e competição intra-específica em soja. Ciência Rural, Santa Maria, v.35, n.6, p.1248-1256, 2005.

MEROTTO JR, A.; SANGOI, L.; ENDER, M.; GUIDOLIN, A.F.; HAVERROTH, H.S. A desuniformidade de emergência reduz o rendimento de grãos de milho. Ciência Rural, Santa Maria, v.29, 
n.4, p.595-601, 1999.

RAVEN, P.H.; EVERT, R.F.; EICHHORN, S.E. Biologia vegetal. Rio de Janeiro: Guanabara Koogan, 2001. 906p.

ROLAS. Recomendações de adubação e calagem para os Estados do Rio Grande do Sul e Santa Catarina. Passo Fundo: SBCSNúcleo Regional Sul, 1994. 224p.

SCHUCH, L.O.B.; NEDEL, J.L.; ASSIS, F.N.; MAIA, M.S. Vigor de sementes e análise de aveia preta. Scientia Agricola, Piracicaba, v.57, n.2, p.305-312, 2000.

VIEIRA, R.D.; CARVALHO, N.M. Teste de vigor em sementes. Jaboticabal: FUNEP,1994.164p.

WALKER, G.K.; BLACKSHAW, R.E.; DEKKER, R. Leaf area and competition for light between plant species using direct sunlight transmission. Weed Technology, Champaingn, v.2, n.2, p.159-165, 1988. 